\title{
Method for calculating the insulation of airborne sound by enclose from volumetric-block buildings
}

\author{
Rakhmatulla Pirmatov $^{1 *}$, Jasur Rashidov ${ }^{2}$ and Khabibullo Pirmatov ${ }^{3}$ \\ ${ }^{1}$ Tashkent State Transport University, Tashkent, Uzbekistan \\ ${ }^{2}$ Tashkent Institute of Architecture and Civil Engineering, Tashkent, Uzbekistan \\ ${ }^{3}$ Tashkent Institute of Irrigation and Agricultural Mechanization Engineers, Tashkent, Uzbekistan
}

\begin{abstract}
This research paper provides a method for calculating airborne sound insulation by encloses from volumetric-block buildings. The choice of the most suitable construction solution for the technical condition of objects at the design stage for building elements should primarily provide insulation from sound and a safe mode inside buildings, in which protection conditions in the combination of energy efficiency and stability should be taken into account, as well as competent decisions and its impact on the construction process buildings.

Numerous scientific studies show the negative effect of sound on human health by the occurrence of various diseases such as cognitive impairment of the fetus in reproductive people, sleep disturbances, tinnitus, irritation, and dysfunction of some human organs. Therefore, sound exposure should be considered a source of inconvenience and a source of harm to human health.

Sound waves collide with the surfaces of enclosing structures, causing them to vibrate and transmit the negative effects of the air around them in adjoining rooms, in which, from the point of view of regulatory requirements, in many cases, it does not meet the requirements, since comfort also depends on the design and sound insulation of the volumetricblock buildings.

Many of these problems are easily solved at the design stage by choosing the right design solution and calculating the soundproofing qualities of the enclosing structures.

In particular, one of the main tasks at the design stage is the development of structural solutions for internal enclosing structures that have a relatively small mass that allows reducing the load on the supporting structures of the building and plummets the material consumption of construction. At the same time, it is necessary to ensure compliance with the regulatory requirements for the isolation of airborne sound of enclosing structures.
\end{abstract}

*Corresponding author: prx55@mail.ru 


\section{Introduction}

At present, in the Republic of Uzbekistan, special attention is paid to ensuring the wellbeing of the people, which is the corresponding goal of implementing the tasks identified in the Strategy of Actions for the Further Development of the Country for 2017-2021 [1]. One of them is the construction of modern buildings.

One of the main conditions for human comfort is to ensure a favorable acoustic regime in the premises, which is achieved through the correct choice of the enclosing structures at the stage of their design.

In a conventional multi-layer wall, for example, erected from two drywall and standardsized racks, vibration is easily transmitted through the structure to the opposite side of the wall, where an intense sound is generated. The soundproofing properties of the airspace are minimized in struts that form a direct connection between two surface masses.

Increasing the mass reduces the vibration amplitude and, therefore, the sound level in the room.

Sound transmission through the enclosing structure can be significantly reduced through the use of elastic membranes, which exclude the direct mechanical effect of drywall with metal struts. The uprights allow doubling the thickness of the sound-absorbing fiberglass insulation in the wall cavity and further reducing direct mechanical connections from one wall surface to another.

In residential buildings, according to regulatory requirements, the airborne sound insulation index must be at least $\mathrm{Rw}=55 \mathrm{~dB}$. Partition envelopes should be designed based on the measured or calculated noise levels on the noisy side of the wall and the target level on the other side of the wall.

Multi-layer partitions are, on average, significantly better than single-layer enclosing structures of the same mass. The exception is the lowest frequencies around the mass-airmass resonant frequency, which is usually in the range of 50 to $300 \mathrm{~Hz}$. In this frequency domain, the sound isolation index locally falls off. Common means of improving the sound insulation of sandwich walls are increasing mass, increasing distance thickness, and increasing absorption within the sound cavity. These methods are usually completely ineffective as large improvements require significant design changes.

The use of sound attenuation techniques to improve the airborne sound insulation index of multi-layer baffles at low frequencies is one of the most important tools.

In general, active noise control works best when the noise contains strong tonal components and is stable.

The improvement in the sound insulation index due to active sound control was at best in the range of between 10 and $40 \mathrm{~dB}$ using sinusoidal excitation. When the primary sound is complete, where there is a bend, then the insulation is reduced. It can be assumed that walls surrounding active systems give the best results when the sound source to be attenuated stationary. Speech or music is probably much more difficult to deal with because it contains rapid vibrations to which electronic systems have no time to adapt.

It is incorrect to assume that insulation with a higher density in the mass-resiliencemass-lightweight envelope provides better sound transmission loss. Comparative tests have shown that an increase in insulation density while maintaining a constant thickness does not significantly affect the sound insulation index of a structure. It is incorrect to assume that heavy insulation in the core of a split wall increases the sound insulation index as it increases the weight of the wall. To increase the sound insulation index of a wall by increasing the weight, the weight must be added to the edges of the wall, not to its sound cavity.

In acoustics and wave mechanics, the problem of oblique incidence of sound on the boundary of media is solved using Snell's laws and Fresnel formulas obtained for light rays 
and well confirmed by optical experiments. In acoustics, the Fresnel formulas for the transmission and reflection coefficients of sound are obtained theoretically by jointly solving the equations of continuity of the vibrational velocity and sound pressure at the boundary of the media and consist of the ratios of the acoustic impedances of the media.

The rays of the incident reflected and transmitted waves are represented by vectors in the form of line segments devoid of transverse dimensions. The continuity conditions are considered at the intersection point of the vectors. That is, in the physical model of sound transmission, the factor of the beam cross-section is excluded from consideration.

One of the conditions for the comfort of the environment is to ensure a favorable acoustic regime in the premises, which is largely achieved by choosing the enclosing structures at the design stage.

In order to increase the factory readiness of prefabricated houses, reduce the time of their construction, improve the quality and rational use of the achievements of science and technology in Uzbekistan, particularly in the city of Tashkent, the method of volume-block construction of residential buildings has been widely introduced.

\section{Methods}

The specificity of buildings made of volumetric blocks is that the internal fencing of horizontally and vertically adjacent blocks is a double enclosing with an air gap and connections along the contour because single-layer encloses do not always provide the required soundproofing ability.

The development of an operational methodology for assessing the insulating capacity of such encloses is highly relevant.

Figure 1 shows a basic structural diagram of internal horizontal (a) and vertical (b) joints between blocks in volume-block buildings.

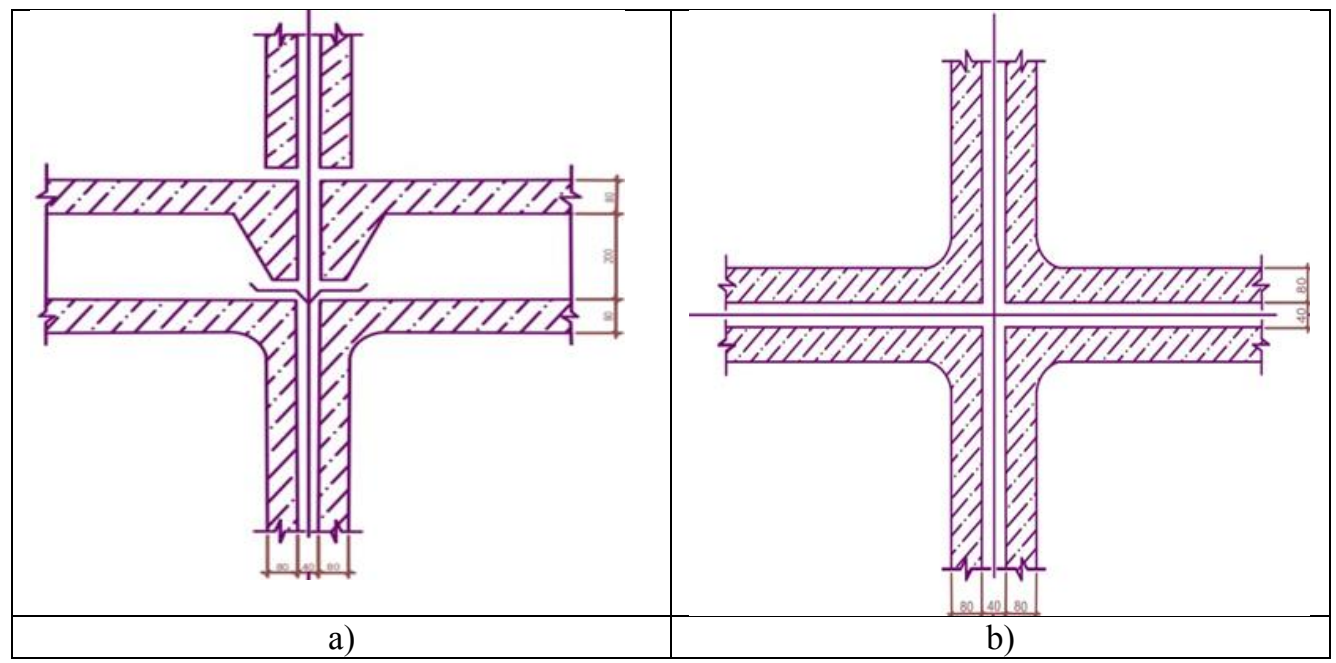

Fig.1. Structural scheme of volumetric-block building: $a$ is internal horizontal joint; $b$ is internal vertical joint

As shown from the figure, the walls and ceiling of the volumetric block are connected to the wall and ceiling of the adjacent block through the airspace, a double fence with an air gap. Sound transmission along indirect paths occurs through the adjoining floor and ceiling structures. 
Consider the isolation of airborne sound by the enclosure of a volume-block building. Figure 2 shows the design diagram and the main sound paths.

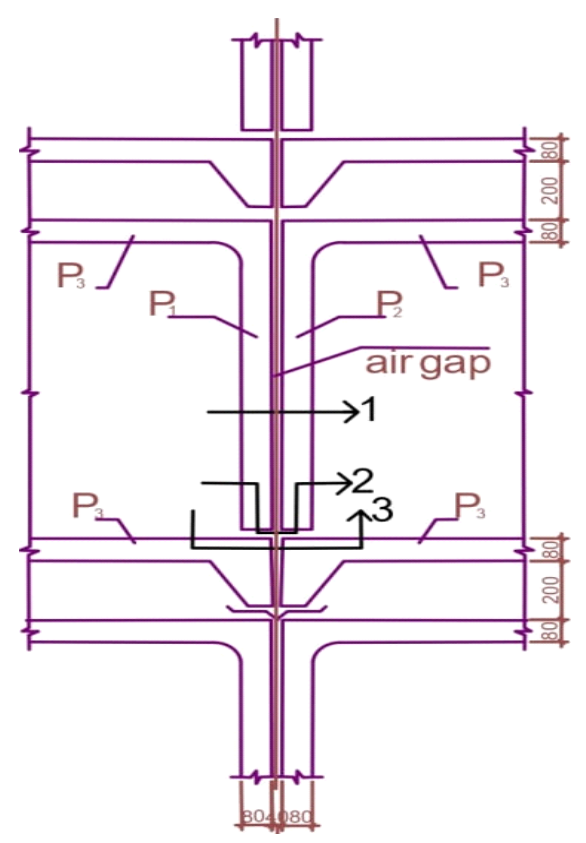

Fig. 2. Design scheme and main paths of sound transmission

Let us denote the density of the material of the first layer through $\rho_{1}$, the second layer $\rho_{2}$, the moduli of elasticity of the materials of the layers, respectively, $E_{1}$ and $E_{2}$, the thickness of the layers $h_{1}$ and $h_{2}$ and the thickness of the air gap through $a[3,4,5,6,7,8]$.

Isolation of sound passing along the path I. The considered enclosing structure along the path $\mathrm{I}$ is represented as a system with one degree of freedom "mass of the enclose elasticity of the air gap - mass of the enclose."

Using the following criteria:

$$
\frac{\ell \omega}{C}<1
$$

where 1 is the size of the body along the direction of propagation of sound vibrations; $\omega=2 \Pi f$ is circular vibration frequency; c is the speed of wave propagation, it is easy to make sure that in ordinary building structures at low and medium frequencies in the thickness of the structural layers and the air gap, the wave motion does not appear. Therefore, sound insulation is determined by two design schemes [2].

1. "waveguide - mass - waveguide";

2. "mass - elasticity - mass".

Due to the instantaneous transmission of motion through all layers, in the calculation according to the first scheme, the mass of one of the structural layers is taken.

The insulation carried out according to the first model is determined by the formula: [2].

$$
R_{1}=20 \lg \frac{\pi \cdot m \cdot f}{\rho_{0} c_{0}}
$$


where $\mathrm{p}_{0} \mathrm{c}_{0}$ is wave resistance of air.

Insulation according to the second model is determined by the well-known formula:

$$
R_{2}=20 \lg \left|1-\left(\frac{f}{f_{01}}\right)^{2}\right|
$$

where $\mathrm{f}_{0}$ is the frequency of natural vibrations of the system "mass - elasticity - mass" is determined from the expression.

$$
f_{0}=60 / \sqrt{a}\left(\sqrt{\frac{m_{1}+m_{2}}{m_{1} \cdot m_{2}}}\right)
$$

where $\mathrm{m}_{1}, \mathrm{~m}_{2}$ is surface densities of the first and second layers.

The total insulating capacity along the path I is:

$$
\mathrm{R}_{\mathrm{I}}=\mathrm{R}_{1}+\mathrm{R}_{2}
$$

Under the condition $\mathrm{f}_{0}>\mathrm{f}_{\text {cutoff1 }}$ and $\mathrm{f}_{\text {cutoff2 }}$, insulation at frequencies below fg $\rho 1$ is defined as sound insulation of a single-layer structure according to the law of mass from the same material, but with an areal density equal to the total surface density of a double enclosure

$$
\mathrm{R}=20 \lg \left(\mathrm{m}_{1}+\mathrm{m}_{2}\right) \cdot \mathrm{f}-48
$$

In the range $f_{\text {cutoff } 1} \div f_{\text {cutoff2 }}$ (region of cutoff frequencies) is a noticeable failure of sound insulation should begin.

Therefore, the insulation values at these frequencies are determined according to the law of masses as for a single-layer structure, with the surface density of a light enclose.

$$
\mathrm{R}=20 \lg \mathrm{m}_{\mathrm{i}} \mathrm{f}-42
$$

At frequencies $\mathrm{f}>\left(\mathrm{f}_{\text {cutoff1 }} \div \mathrm{f}_{\text {cutoff } 2}\right)$ (the region above the cutoff frequencies), taking into account the design schemes given in [3], which shows two variants (at large and small angles of incidence of sound) of wave coincidence. If we compare these two options, we can see that in the first case, the transmission of oscillatory motion occurs according to the "waveguide - mass - waveguide" scheme, and in the second - according to the "waveguide waveguides" scheme. The basis for choosing this calculation scheme is the fact that the incident sound wave simultaneously excites two waves: one into the plate, the other in the medium behind the plate (in this case, also due to the "instantaneousness," the transmission of motion through all layers, we take into account the mass of the more massive layer).

To obtain the insulation formula, we use formula (2), taking into account the angles, replacing the distributed mass of the layer in it with the expression for the reduced mass of the more massive layer:

$$
\mu=\frac{m_{n \pi} \cdot \lambda_{n \pi}}{2 \pi}
$$


Reduced air mass

$$
\mu_{B}=\frac{\rho \cdot \lambda \cdot \theta}{2 \pi}=\frac{\rho_{0} \lambda_{0} \cdot \lambda_{n \pi} \cdot \cos o}{2 \pi}
$$

Substituting the obtained expression (8-9) into the expression for the transmission coefficient of the vibration velocity from [3] at $\mu<<$ m

$$
\begin{gathered}
\alpha=\frac{2 \mu_{b}}{m \cdot \cos o} \\
\alpha=\frac{2 \mu_{B} \cdot 2 \pi}{m_{n л} \cdot \lambda_{n л} \cdot \cos o}=\frac{2 \rho_{0} c_{0}}{m_{n л} \cdot f}
\end{gathered}
$$

Sound insulation accordingly:

$$
R=10 \lg \frac{1}{\alpha^{2}}=20 \lg \frac{m_{n \pi} \cdot f}{2 \cdot \rho_{0} c_{0}}
$$

In the frequency range $<\omega_{0}=\omega<$ within which the natural frequency is located, the insulation is reduced by $6 \mathrm{~dB}$ from the value calculated according to $(5,6,7,12)$.

At frequencies $\mathrm{f} \geq \mathrm{f}$, where the wave motion appears itself in the air gap, the computational model consists of three successive collisions of reduced masses.

Sound insulation is defined as the sum of the insulation of the individual links.

$$
\mathrm{R}=\mathrm{R}_{1}+\mathrm{R}_{2}+\mathrm{R}_{3}
$$

The limiting frequency of the air gap is determined by the formula:

$$
f_{n p_{6}}=\frac{C}{6 a}
$$

However, at frequencies $\mathrm{f}>\mathrm{f}_{0}$, the isolation value is determined by indirect transmission paths (paths II and III).

Those, the transmission of sound occurs along with the structures of buildings through the joints.

Insulation values are determined by the formulas:

$$
\begin{aligned}
\mathrm{R}_{\mathrm{ly1}}=\mathrm{R}_{1}+\Delta \mathrm{R}_{\mathrm{j}} \\
\mathrm{R}_{\mathrm{ly} 2}=\mathrm{R}_{3}+\Delta \mathrm{R}_{\mathrm{j}}
\end{aligned}
$$

Where, $\mathrm{R}_{1}$ is isolation of a more massive layer of the fence is determined by the method described in the work [2];

$\mathrm{R}_{3}$ is the insulation of the adjoining structure (walls or floors) is also determined by the method described in the work [2];

$\Delta \mathrm{R}_{\mathrm{j}}$ is the insulation of the joint of the fence in question with adjacent structures is taken based on the ratio $h_{1} / h_{3}$ or $h_{3} / h_{1}$, according to the graph or expressions obtained taking into account linear approximation 


$$
\begin{gathered}
\quad \text { if } \quad \begin{aligned}
0.5 & <\left(\mathrm{h}_{1} / \mathrm{h}_{3} \text { or } \mathrm{h}_{3} / \mathrm{h}_{1}\right)<1.5 \text { then } \\
\Delta \mathrm{R}_{\mathrm{j}} & =5.5+0.5(\mathrm{n}-1) \mathrm{dB} ; \\
1.5 & \leq\left(\mathrm{h}_{1} / \mathrm{h}_{3} \text { or } \mathrm{h}_{3} / \mathrm{h}_{1}\right)<2.5 \text { then } \\
\Delta \mathrm{R}_{\mathrm{j}} & =11.5+0.5(\mathrm{n}-1) \mathrm{dB} ; \\
2.5 & \leq\left(\mathrm{h}_{1} / \mathrm{h}_{3} \text { or } \mathrm{h}_{3} / \mathrm{h}_{1}\right)<7.5 \text { then } \\
& \text { if } \quad \mathrm{R}_{\mathrm{j}}=18.0+0.5(\mathrm{n}-1) \quad \mathrm{dB} .
\end{aligned} \text { if }
\end{gathered}
$$

Where, $\mathrm{n}$ is octave number. (15).

In the final calculation, the lower insulation value is taken from the values $R_{l y 1}$ and $R_{l y 2}$

\section{Results and Discussion}

Consider the soundproofing of internal encloses of residential buildings from volumetric blocks built in Tashkent. The walls are made of heavy concrete with a thickness of each layer of $0.08 \mathrm{~m}$; the air gap is a $=40 \mathrm{~mm}$, the ratio of the thicknesses of the elements of adjoining structures is $\mathrm{h}_{1} / \mathrm{h}_{3}=1$.

The cut-off frequency of individual layers in the region $f_{1}=f_{2}=494 \mathrm{~Hz}$. The frequency of natural vibrations of the system "mass - elasticity of the air gap - mass" is $f_{0}=31 \mathrm{~Hz}$, i.e., $f_{0}<f_{1}$ and $f_{2}$. Since $f>f_{0}$, the sound insulation of the fence is determined entirely by the structural component, i.e., indirect transmission routes.

Fig. 3 shows the frequency response calculated by the proposed methodology and experimental calculations.

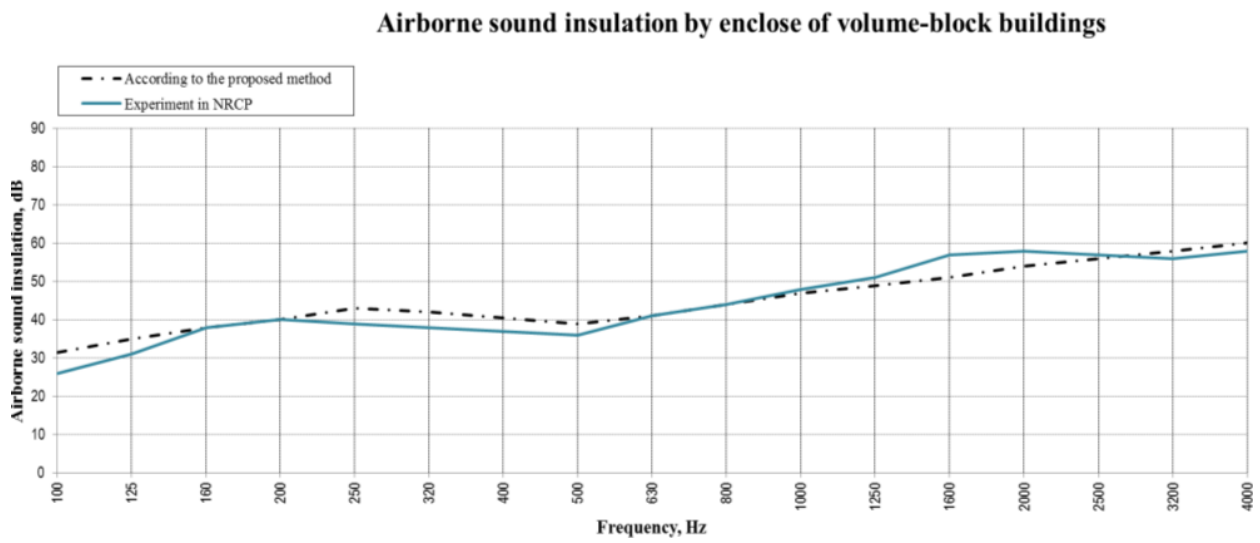

Fig. 3. Frequency response of airborne sound insulation of building enclosures from volumetric blocks: 1 is according to the proposed method; 2 is experiment NRCP.

The results of the calculation by the proposed method are in satisfactory agreement with the calculations by the experiment. The results of experimental studies were carried out by NRCP in buildings constructed in Kharkov, Ukraine.

\section{Conclusion}

Thus, this technique makes it possible to determine simply and quickly the indirect ways of transferring the internal encloses of residential buildings from volumetric blocks. Using this methodology, design engineers can compare technical design solutions based on various criteria following their characteristics and capabilities during the design or renovation phase of buildings to assess the most important aspects of buildings. 


\section{References}

1. Normative document of 2.01. 08-19 Noise protection, Tashkent, (2019)

2. Pirmatov R.Kh., Zakharov A. V.,Rashidov J.G, Graphical method for calculating sound insulation of air noise of single layer enclosing structures. International Journal of Advanced Research in Science, Engineering and Technology.India. 6/7/2019, pp 10294-10298. (2019).

3. Pirmatov R.Kh., Zakharov A.V. About the dependence of sound transmission on the angle of incidence on the boundary of media or a massive layer, Journal of Problems of Mechanics. 1. pp. 50-55. (2018)

4. Pirmatov R. Reducing the noise of built-in power equipment in civil buildings, (1991)

5. Zakharov A.V., Fazylov A.R., and Pirmatov R.K. Acoustic oscillations of rods and plates. USSR Rept Eng Equipment JPRS UEQ 2, p. 92. (1985)

6. Zakharov A.V. Discrete models of passage of waves for calculation of sound insulation in buildings. Industrial and Civil Engineering pp. 50-54, (2012)

7. Zakharov A. About some misunderstandings in the modern theory of the sound isolation and discrete models of sound transmission. Applied Mechanics and Materials, 467, pp. 361-366, (2013).

8. Normative regulations 23-103-2003 "Design of soundproofing of enclosing structures of residential and public buildings". Ministry of Construction of Russia, p. 34, (2004)

9. Pirmatov, Rakhmatilla Khamidullaevich, and Jasur Gayrat Ugli Rashidov. Research Of The Acoustic Parameters Of Halls And Practical Methods Of Eliminating Acoustic Defects. The American Journal of Engineering and Technology 2.(12), pp 7-13. (2020)

10. Rashidov, Jasur. Measuring sound insulation of air noise." Theoretical \& Applied Science 12 pp 121-123. (2019),

11. Júnior, Otávio JS, et al. Sound insulation of gypsum block partitions: An analysis of single and double walls. Journal of Building Engineering 39 p 102253. (2021).

12. Khamidullaevich, P. R., S. E. Vladimirovna, and Ugli RJ Gayrat. On peculiarities of formation of the thermal mode in operating panel buildings. International Journal of Scientific and Technology Research 8.(10) pp 2533-2535. (2019)

13. Shaumarov, S. S., E. V. Shchipacheva, and R. Kh Pirmatov. Prospects for further operation of panel residential buildings. Materials of the 12th International Scientific and Practical Conference" Prospects for the Development of Construction Technologies"/Dnepropetrovsk. (2018).

14. Pirmatov R., and Urozimbatova G. Prospects for further exploitation of panel residential buildings. Development of modern science: theoretical and applied aspects, pp. 47-50, (2016)

15. Nurzyński, Jacek. Sound insulation of bulkhead panels. Applied Acoustics 179, p. 108061. (2021)

16. Roozen N. B. On the use of dynamic vibration absorbers to counteract the loss of sound insulation due to mass-spring-mass resonance effects in external thermal insulation composite systems. Applied Acoustics 178, p. 107999. (2021)

17. Batko W., and P. Pawlik. New method of uncertainty evaluation of the sound insulation of partitions. Acta Physica Polonica A 123, (6). pp. 1012-1015, (2013)

18. Uris, Antonio, et al. Experimental sound insulation performance of double frame partitions with slits. Applied acoustics 69, (10). pp. 918-924, (2008)

19. Hongisto, Valtteri, Maria Mäkilä, and Maija Suokas. Satisfaction with sound insulation in residential dwellings-The effect of wall construction. Building and environment 85 pp 309-320. (2015).

20. Hopkins, Carl. Sound insulation. Routledge, (2012). 